\title{
Review on Strategy of Developing Intercropping Practices
}

\author{
Solomon Teshome \\ Oromia Agricultural Research Institute, Bore Agricultural Research Center, Bore, Ethiopia
}

\begin{abstract}
Intercropping offers greater financial returns for a farmer. Intercropping will help farmers use the same land as available and yield more as well as diverse produce. It can be the insurance that farmers need, especially when the region is vulnerable to weather extremes. Drought, torrential rain, hurricanes or cyclones and various other weather elements can affect the yield of a given year or season. Conventional farming and mono-cropping systems in addition to depletion the natural resource, is caused environmental pollution. Intercropping can be defined as a multiple cropping system that two or more crops planted in a field during a growing season. Whatever the crop combinations, intercropping is an intensive and sustainable land use system which the farmer has evolved over the years through experimentation. The result of this review imply that development interventions realizing the economic and environmental potential of legumes-cereal crops will help to achieve a double goal of enhancing the livelihoods of households
\end{abstract}

Keywords: intercropping, mono-cropping

DOI: $10.7176 / J N S R / 9-3-04$

\section{INTRODUCTION}

Agricultural sector has important economic activities in various communities requires coherent planning in order to achieve development and confront with crises. One of the main needs of each dynamic activity is planning within the general objectives on it activities. Sustainable agriculture is a type of agriculture that is more efficient in use of resources, for the benefit of human, and is in balance with the environment. In other words, sustainable agriculture must be ecologically appropriate, economically justified and socially desirable. Objectives of sustainable agriculture have a closely associated with its definitions; objectives of the successful sustainable agriculture program are the following: provide food security along with increased quality and quantity, with considering the needs of future generations; conservation of water, soil and natural resources; conservation of energy resources inside and outside the farm; maintain and improving farmers profitability; maintain the vitality of rural communities; conservation of biodiversity (Eskandari, 2012).

In conventional farming and mono-cropping systems, although high yield per unit area is been able to provide the nutritional needs of growing populations in some areas, but these systems requires direct and indirect to abundant costs and energy that arise from fossil fuels. In terms of ecology and environment, mono-cropping has been caused a series of serious problems. Human by excessive use of resources such as water, soil, forests, pastures and natural resources not only put them at risk of extinction, but also with the creation of pollution caused by industrial activities, chemical fertilizers and pesticides, threatens the earth (Reganold, 1992). If farming activities be conducted based on ecological principles, in addition to preventing the destruction of natural ecosystems, the result is stable condition (Mazaheri et al., 2006). Also agricultural systems must provide needs of people today and future generations; therefore it seems that is essential achieving to sustainable agriculture. One of the key strategies in sustainable agriculture is restoration diversity to agricultural ecosystems, and its effective management. Intercropping is a ways to increase diversity in an agricultural ecosystem. Intercropping as an example of sustainable agricultural systems following objectives such as: ecological balance, more utilization of resources, increasing the quantity and quality and reduce yield damage to pests, diseases and weeds. Success of intercrops in comparison with a pure cropping can be determined by a series of agronomic operations that interactions between the species will be affected by them. These operations are including ultimate density, planting date, resources availability and intercropping models (Mousavi and Eskandari, 2011).

Over the past two decades, there has been an accelerated interest in the entire range of component technology for intercropping: breeding new hybrids or varieties, determining fertility needs, assessing weed and other pest management strategies, and designing alternative systems. Most treatments have been evaluated using traditional measures of productivity grain yield per hectare, net income per hectare. However, it is likely that these are neither the only nor perhaps the primary criteria used by limited resource farmers to evaluate their own success. Such priority questions as return to labor, risk of adopting new technology, stability and sustainability of production, nutritional and other food quality factors may in fact be more important to the farm family. Complex questions in farming systems may be more easily studied across a wide range of climatic conditions through simulation research. This would require credible baseline data, relevant measures of system productivity in terms or units which are meaningful to farmers, and careful consideration of the appropriate levels of inputs and resources. Interdisciplinary team approaches are essential to understanding the complexity of intercropping and how systems can be manipulated to increase productivity and sustainability (Palmer and Edje, 1989). 
Intercropping, the simultaneous cultivation of more than one species or cultivar on the same piece of land, can increase organic cereal and grain legume protein production in Europe, enhance biodiversity in European farming systems and safeguard the organic farmers' earnings. Despite its advantages, intercropping has traditionally been neglected in research on plant production systems in temperate agricultural ecosystems, due to its complexity and because of the difficulties for its management and lesser relevance in cropping systems based on agrochemicals. Intercropping has many advantages, mainly related to the complementary use of environmental resources by the component crops which results in increased and more stable yields, better nutrient recycling in the soil, better control of weeds, pests and diseases and an increased biodiversity. Cereals and legumes, both for forage and for grain, are the most common intercrops. The main advantage of the legume-cereal intercrop is the input of nitrogen to the system by the fixation of atmospheric N2 by the legume, which results in improved use of renewable nitrogen sources (Menale, 2011).

Regionally differentiated interventions benefitting to the natural resource endowment, social capital, and economic condition are need of the hour to meet the current challenges. For this, it is important to prioritize crops that match and identify the possible interventions for formulating cropping systems. In view of the above, there is an urgent need to prioritize the cropping systems based on resource availability and livelihood parameters. Therefore, this paper deals with the earlier and best efforts on classifying, reviewing, developing and introducing best cropping practices of intercropping with its strategy.

\section{INTERCROPPING CONCEPTS}

\subsection{Strategies for Developing the Practice}

Although there is no recorded history for intercropping and multiple cropping, however, considering the available evidence planting crops as a combined has a long history. Intercropping is as a multiple cropping system, in which two or more crops species planted simultaneously in a field during a growing season. Of course this does not mean that in the intercropping, plants can be planting at a time together, but is the purpose that two or more crops are together in one place, during their growing season or at least in a timeframe. Therefore is possible that the plants are different in terms of planting time, and a plant is planted after the first plant. Current food crises in a number of countries demand attention from the agricultural research community. We need to carefully examine the research and extension agenda, as well as the specific methods available for developing and introducing cropping system. Also agricultural systems must provide needs of people today and future generations; therefore it seems that is essential achieving to sustainable agriculture. One of the key strategies for sustainable agriculture is restoration diversity to agricultural ecosystems, and its effective management. These operations are including ultimate density, planting date, resources availability and intercropping models. (Mazaheri et al., 2006).

Most grain-crop mixtures with similar ripening times cannot be machine-harvested to produce a marketable commodity since few buyers purchase mixed grains. Because of limited harvest options with that type of intercropping, farmers are left with the options of hand harvesting, grazing crops in the field with animals, or harvesting the mixture for on-farm animal feed. However, some intercropping schemes allow for staggered harvest dates that keep crop species separated. Another example is planting harvestable strips, also known as strip cropping. When two or more crops are growing together, each must have adequate space to maximize cooperation and minimize competition between them. Intercropping offers farmers the opportunity to engage nature's principle of diversity on their farms. Spatial arrangements of plants, planting rates, and maturity dates must be considered when planning intercrops (Martin et al., 1987).

The first reaction of research specialists to a challenge of improving productivity of intercropping systems often has been to recommend monoculture. Trained in the tradition of sole cropping technology and efficiency, such scientists are reacting in a predictable, though perhaps irrational, manner to a situation which they do not understand well. There is certainly value in searching among the available systems and technologies for solutions to priority problems; there is neither time nor sufficient resources to research problems which are not really limiting production on the small farm. What are some potential strategies that are efficient in resource use and carefully directed toward priority problems on the farm? First it is important to work on systems which are used by farmers and that have researchable problems susceptible to solution. In the following example, it is assumed that the maize bean intercropping system has priority for farmers in the region of interest. The methods developed could be applied to any system. One approach to sorting out the near-infinite potential research topics that could be explored in an intercropping system is to prioritize the factors limiting yields and the most likely interactions among those factors. Many different types of cropping systems have been developed in agriculture in order to cope with climate extremes. Crop and soil in agriculture are managed to produce maximum yield with less risk against extreme climate using limited resources. At the other end of the spectrum, the farming systems approach leads us to carefully examine the systems being used by farmers in each domain, and to focus research on those elements considered by the farmer to be most limiting to yields (Gilbert et al., 1980 cited in Palmer and Edje, 1989).

Intercropping is a ways to increase diversity in an agricultural ecosystem. Intercropping as an example of sustainable agricultural systems following objectives such as: ecological balance, more utilization of resources, 
increasing the quantity and quality and reduce yield damage to pests, diseases and weeds. Success of intercrops in comparison with a pure cropping can be determined by a series of agronomic operations that interactions between the species will be affected by them (John and Mini, 2005).

\subsection{Factors Affecting Intercropping Practices}

On-farm research is sometimes confused with research on multiple cropping. Although the two overlap, they are different. On-farm research usually works on stepwise modifications to existing farming systems, starting from an understanding of farmers' circumstances, practices, problems and objectives. The existing farming systems are often, but not always, multiple cropping systems. Multiple cropping researches has often been conducted on experiment stations with the aim of proving or understanding the efficiency of multiple cropping systems, or of designing new systems on the basis of biological principles. The single - strip or row intercropping pattern, used among farmers in Magoye, Zambia, is usually encountered in small-scale agriculture. Farmers with little or no education showed no willingness to incorporate intercropping into their farming systems even if a suitable intercrop was identified. The study further showed that gender and literacy level of a farmer had a significant influence on the attitude of a farmer towards intercropping. With increased education, the farmer was more likely to practice intercropping. In the African set - up, gender inequalities in agriculture means that women farmers have limited access to financial resources and they have no or minimal involvement in the decision making process regarding agricultural development at household level. Availability of labor is a major socio economic factor that affects the adoption of agricultural technology (Mutibo, 2011).

\subsection{Factors Affecting Adoption of Intercropping Practices}

The biggest obstacle in adopting intercropping systems is to conceptualize the planting, cultivation, fertilization, spraying, and, particularly, harvesting of more than one crop in the same field. Agronomic recommendations simply do not exist. Furthermore, given the numerous intercrop combinations possible and the myriad of climatic and soil conditions involved, generalization to recommendations may not be possible. Once the potential benefits of intercropping are realized, and the will develops, mechanization could be developed for these potentially beneficial systems, but it will take a long time before mechanized intercropping systems will rival the current monoculture systems. Given the advantages to be enjoyed from intercropping and the environmental and economic problems with current farming systems, it seems reasonable to continue research on the possibilities of growing more than one crop in a field at the same time (FAO, 2008).

The agriculture and economy of Mauritius are still dominated by the sugar industry in spite of major structural changes that have taken place in the economy during the past 10 years. Sugar cane occupies more than $90 \%$ of the area under cultivation and there are few prospects for developing more land for cropping. Sugar and cane byproducts represent $90 \%$ of agricultural exports and $40 \%$ of total exports, but the food import bill absorbs a good part of the earnings from sugar. Interest in intercropping was revived in the late 1960's when the present strategy of agricultural diversification was proposed, and when a Food Crop Agronomy Division was created. Potato is at present the most successful intercrop of sugar cane. A fairly complete package of technology has been developed and it has been widely adopted by all farmer groups; small growers and large estates each account for about half of the total production. This success is attributable in large measure to the fact that potato does not reduce the yield of intercropped sugar cane and conversely, sugar cane does not affect potato yields (Palmer and Edje, 1989).

The survey revealed that farmers in Zambia of Magoye area were using two types of cultural practices to control insect pests in their cotton fields, these were; crop rotation $(72.5 \%)$ and intercropping plus crop rotation $(27.5 \%)$. The intercrops were grown either as a strip/single row pattern alongside the cotton crop or in between each row of cotton. The farmers in this area were using four different types of crops namely: maize, cowpea, beans and groundnuts with cowpea and beans being the most common combination (22\%) of intercrops used. Qualitative responses to the survey indicated that the gender and educational level of a farmer were one of the main factors that affect a farmer's willingness to adopt intercropping (Braun, 1991). Generally, Farmer adoption of intercropping methods is usually strongly constrained by the need for the intercrop to show significant direct economic benefits and this will depend on many factors that are unrelated.

\subsection{Role of Intercropping in Modern Agriculture}

Intercropping is growing two or more crops at the same time on a single field is an ancient practice still used in much of the developing world. For example, in Africa, corn (Zea mays L.), sorghum (Sorghum bicolor (L.) Moench), or millet (Panicum and Pennisetum spp.) are grown with pumpkin (Cucurbita spp.) cowpeas (Vigna unguiculata (L.) Walp), pigeon peas (Cajanus cajan (L.) Millsp.), or beans (Phaseolus spp.). Before the 1940s in the United States and Europe, growing more than one crop in the same field was common practice (Kass 1978; Andersen 2005), again because there was less risk. But with mechanization and the availability of relatively cheap synthetic fertilizers and pesticides, mono cropping i.e., growing only one crop in a field at a time became the economically efficient way to go. Intercropping has four general subcategories. There is mixed intercropping, no 
distinct row arrangement; row intercropping, at least one crop is planted in rows; strip intercropping, growing crops in strips wide enough to separate them, yet narrow enough to allow interaction between them; and relay intercropping, growing two or more crops during differing parts of their life cycles. Whenever two crops are planted together they will interact either or both in competition (for light, water, and nutrients) and facilitation. The success of an intercrop system depends on understanding the physiology of the species to be grown together, their growth habits, canopy and root architecture, and water and nutrient use. Plants compete for light above ground and for water and nutrients below grown, so competition involves a combination of light and soil factors in space and time. What begins as a nutrient competition may end up as a shade issue, as different species compete for various resources at differing times in their growth cycle. This complexity may be discouraging research in these areas. If intercropping is, indeed, experiencing a renaissance in response to problems with monoculture, this should not be seen as going back to ancient peasant ways, but, rather, as adopting useful aspects of the practice to modern agriculture. However, the methods described above will likely find their best use in modern organic farming. In fact, organic farming is a perfect fit for intercropping as fossil-fuel-based inputs. Intercropping can also fit into conventional cropping systems. Intercropping provides increased diversity, which facilitates better biological control of pests and reduced soil erosion. Legumes intercropped with cereals can provide not only nitrogen, but also other minerals, soil cover, as they also smother weeds, and increase microbial diversity, such as vesicular arbuscular mycorrhizae (VAM). VAM, a fungus, plays an interesting role in that it is thought to facilitate nutrient transfer (Horwith, 1985).

\subsection{Importance of Intercropping}

Intercropping ensures efficient utilization of light and other resources, reduces soil erosion, suppresses weed growth, and thereby helps to maintain greater stability in crop yields. It also guarantees greater land occupancy and thereby higher net returns. One important reason intercropping is popular in the developing world is that it is more stable than mono-cropping. In Africa and South Asia, where environmental stress is common, intercropping is an insurance against total crop failure. The stability under intercropping is attributed to the partial restoration of diversity lost under mono-cropping. The most well documented advantage of intercropping is reduced damage from insects, nematodes, and disease. Intercropping systems often exhibit less crop damage associated with insect and plant pathogen attacks, although the results are quite variable. Previous research has shown a reduction of insect damage in intercropped systems compared to monocultures (Machado, 2009).

Intercropping with a cover crop often provides weed control in the cropping system. One proposed mechanism of weed control is competition of the secondary crop with weed species. Individual intercropping systems show more variable weed control effects. For example, a maize-cowpea intercrop in Nigeria had no suppressive effect on weeds early in the season, but controlled weed growth effectively later in the cropping season. On the other hand, a maize-cassava system at the same location did not suppress weed growth Again, while reviews of research on intercropping and weed control arc impressive, individual cropping systems respond differently and, therefore, must be evaluated on their own merit based on site-specific conditions and the crops used (Unamma and Ene, 1983). Intercropping with legumes may have either beneficial or detrimental effects because inter specific competition, the nitrogen-fixing capacity of the legumes, planting times, and soil fertility levels can affect nutrient accruement. One interpretation of this advantage is that the non-legume component uses soil $\mathrm{N}$, while the legume component uses $\mathrm{N}$ from the atmosphere. The legume-cereal inter cropping can be beneficial when the cropping system is managed to minimize inter specific competition (Sanchez, 1976).

The purpose of intercropping is to generate beneficial biological Interactions between the crops. Intercropping can increase grain yields and stability, more efficiently use available resources, reduce weed pressure and sustain plant health. Mixing species in cropping systems may lead to a range of benefits that are expressed on various space and time scales, from a short-term increase in crop yield and quality, to longer-term agro ecosystem sustainability, up to societal and ecological benefits. Intercropping has many advantages, mainly related to the complementary use of environmental resources by the component crops which results in increased and more stable yields, better nutrient recycling in the soil, better control of weeds, pests and diseases and an increased biodiversity. Cereals and legumes, both for forage and for grain, are the most common intercrops. The main advantage of the legume-cereal intercrop is the input of nitrogen to the system by the fixation of atmospheric N2 by the legume, which results in improved use of renewable nitrogen sources (Lauk R.and Lauk E., 2005).

\section{SUMMARY}

In conventional farming and mono cropping systems, although high yield per unit area is been able to provide the nutritional needs of growing populations in some areas, but these systems requires direct and indirect to abundant costs and energy that arise from fossil fuels. In terms of ecology and environment, mono cropping has been caused a series of serious problems. If farming activities be conducted based on ecological principles, in addition to preventing the destruction of natural ecosystems, the result is stable condition. Intercropping is an example of sustainable agricultural systems following objectives such as: ecological balance, more utilization of resources, 
increasing the quantity and quality and reduce yield damage to pests, diseases and weeds (Mousavi and Eskandari, 2011).

Most intercropping systems exhibit competition for $\mathrm{N}$ between crop components. Legume-cereal intercropping systems have less $\mathrm{N}$ competition when legumes are fixing $\mathrm{N}$ actively. If $\mathrm{N}$ fixation is inhibited, the legume behaves like other crop species and competes for soil $\mathrm{N}$ actively. The management of crop growth stages played an important role in $\mathrm{N}$ competition. When corn and sorghum (Sorghum spp.) had simultaneous maximum $\mathrm{N}$ demands, yields of both crops were reduced drastically. Intercropping of non-legumes with legumes increased the $\mathrm{N}$ fixation of the legume component. Their results showed that non-legume components had a competitive advantage for soil $\mathrm{N}$ that forced legume components to maximize their biological $\mathrm{N}$ fixing capabilities. They contend that legumes generally take a subordinate role in legume-cereal inter cropping (Sanchez, 1976).

Female farmers are less likely to adopt intercropping as they may not have the financial resource to experiment with the technology, the required labor to manage the crop and the power to make the decision about the technology (Adeoti, 1999 cited in Braun, 2009). Availability of labor is a major socio economic factor that affects the adoption of agricultural technology among African small -scale farmers. The majority of female farmers will not have the extra skilled man power required to manage an intercropping pest management strategy. Therefore the dominance of gender inequality in the agricultural sector presents a bottleneck to the development of intercropping pest management strategy (Braun, 1991).

The adoption of intercropping systems has a number of potential advantages and disadvantages that are often site and crop specific. Intercropping can be a more-efficient means of exploiting the resources required for plant growth. Relay-planting crop components so that resource demands occur during different periods of the growing season can be an effective means of minimizing inter-specific competition. Yet, little is known about root interactions in individual intercropping systems, which makes it difficult to predict yields, use of resources, or biological interactions for a given system. The effect of intercropping on insect, nematode, disease, and weed problems is site-specific and difficult to predict and, therefore, must be evaluated for each new intercropping combination (Coolman and Hoyt, 1993).

There is urgent need to increase food production to feed the rising population, the majority which is concentrated in urban areas. Appropriate research interventions in developing technologies that will ensure sustainable crop production without adversely affecting the natural resource base are required, like cropping system. Government policies relating to agriculture require re-examination to provide an enabling environment for increased participation of the private sector. Increased participation of all stakeholders including farmers, natural and social scientists together with extension agents will ensure proper identification of problems and greater chances of finding appropriate solutions.

Careful and possible intervention strategy into the predominant cropping systems should be given attention. Possible interventions should include:

I. Developing varieties of these crops that are compatible with associated crops

II. Establishing effective multiplication and distribution schemes for the improved planting materials of those varieties

III. Determining appropriate times of planting the intercrops

IV. Determining appropriate fertilization rates and regimes

V. Developing appropriate planting patterns

VI. Developing appropriate machinery for key tasks such as planting, weeding fertilizing harvesting and,

VII. Strengthening the linkage between research institutions, technology transfer institutions and farmer's organizations should have to make strong intervention strategy (Mousavi, and Eskandari, 2011).

Whatever the crop combinations, intercropping is an intensive and sustainable land use system which the farmer has evolved over the years through experimentation. Because of the current human population pressures on our fragile and deteriorating ecosystem and shrinking arable land, intercropping will become more important not only for the smallholder farmer but also for the estate sector too. In sum, different researches imply that development interventions realizing the economic and environmental potential of legumes-cereal crops will help to achieve a double goal of enhancing the livelihoods of households and at the same time preventing land degradation.

\section{REFERENCES}

1. Braun M. 2009. IPM Training Manual: Tanzanian German IPM project GTZ. Chinyanga.Tanzania.

2. Coolman R.M. and Hoyt G.D., 1993. Increasing Sustainability by Intercropping. North Carolina State University. (Accessed on November 16, 2013).

3. Eskandari H., 2012. Yield and quality of forage produced in intercropping of maize (Zeamays) with cowpea (Vigna sinensis) and mungbean (Vigna radiate) as double cropped. Journal of Basic and Applied Scientific Research.

4. Food and Agricultural Organization. 2008. Current World Fertilizer Trends and Outlook to 2011/12. vol. 64, 
Rome: Food and Agriculture Organization, United Nations.

5. John S.A and Mini C, 2005. Biological efficiency of intercropping in okra 43 (1-2). Kerala Agricultural University, Kerala, India.

6. Machado S, 2009. Does intercropping have a role in modern agriculture? Journal of soil and Water conservation. North New Hope. (www.truaxcomp.com). (Accessed on November 13, 2013).

7. Lauk R. and Lauk E., 2005. The yields of legume-cereal mix in years with high precipitation vegetation periods. Institute of Agriculture, Lithuanian Research Centre for Agriculture and Forestry. Lithuania. (Accessed online December 4, 2013).

8. Martin, Ralph, Don S., and Harvey V. 1987. Intercropping corn and soybeans. Sustainable Farming. REAP Canada. McGill University, Macdonald Campus.http://www.eap.mcgill.ca/. (Accessed on December 6, 2013).

9. Mazaheri, D., A. Madani and M. Oveysi, 2006. Assessing the land equivalent ratio (LER) of two corn (Zea mays L.) varieties intercropping at various nitrogen levels in Karaj, Iran.www.textroad.com (Accessed online on November 14, 2013).

10. Menale K, 2011.Economic and Environmental Benefits of Forage Legume Intercropping in the Mixed System: Ethiopia. http://www.edri.org.et/. (Accessed online on December 2, 2013).

11. Mousavi, S.R. and H. Eskandari, 2011. A General Overview on Intercropping and Its Advantages in Sustainable Agriculture. Journal of Applied Environmental and Biological Sciences. 1(11)482-486, 2011.

12. Mutibo C. 2011. Factors Affecting a Farmer's Willingness to Adopt Intercropping in Cotton: Cotton Development Trust. Zambia.

13. Reganold, J.P., 1992. Effects of alternative and conventional farming systems on agricultural sustainability. Department of Crop and Soil Sciences. Washington, USA.

14. Sanchez, P.A. 1976. Properties and management of soils in the tropics. Wiley, New York.p. 478-532.

15. Unamma, R.P.A. and L.S.O. Ene. 1983. Weed interference in cassava-maize intercrop in the rainforest of Nigeria. Tropical root crop production and uses in Africa. Proc. $2^{\text {nd }}$ Triennial Symp. Intl. Soc. Trop. Root Crops. Africa Branch IDRC. 